\title{
Comparison on modifications of vanadium oxide thin films by single-walled and multi-walled carbon nanotubes
}

\author{
Qiong $\mathrm{He}^{1}$, Xiangdong $\mathrm{Xu}^{1}{ }^{1} \mathrm{a}^{*}, \mathrm{Yu} \mathrm{Gu}{ }^{1}$, Xinrong $\mathrm{Li}^{1}$, Minghui Sun ${ }^{1}$, \\ Xiaomeng Cheng ${ }^{1}$, Yadong Jiang ${ }^{1}$ \\ ${ }^{1}$ State Key Laboratory of Electronic Thin Films and Integrated Devices, School of Optoelectronic \\ Information, University of Electronic Science and Technology of China, Chengdu 610054 \\ ${ }^{a} x d x u @ u e s t c . e d u . c n$
}

Keywords: Vanadium oxide, Carbon nanotube, Composite thin films

\begin{abstract}
Vanadium oxide-Multi walled carbon nanotube $\left(\mathrm{VO}_{\mathrm{x}}-\mathrm{MWCNT}\right)$ and vanadium oxide-Single walled carbon nanotube $\left(\mathrm{VO}_{\mathrm{x}}-\mathrm{SWCNT}\right)$ were prepared by sol-gel process and systematically investigated. Results reveal that if MWCNTs are incorporated with $\mathrm{VO}_{\mathrm{x}}$ to form the $\mathrm{VO}_{\mathrm{x}}-\mathrm{MWCNT}$ composite film, the $\mathrm{VO}_{\mathrm{x}}$ can strongly interact with MWCNTs, thus significantly modifying the chemical structures, crystallinity, and electrical properties of $\mathrm{VO}_{\mathrm{x}}$. Interestingly, under the similar conditions, the interactions between SWCNT and $\mathrm{VO}_{\mathrm{x}}$ are weaker, leading to a moderate adjustment on the overall properties of $\mathrm{VO}_{\mathrm{x}}$. This work reveals the modifications of CNTs on the chemical structures and physical properties of $\mathrm{VO}_{\mathrm{x}}$, and particularly, the different influences between MWCNTs and SWCNTs on the $\mathrm{VO}_{\mathrm{x}}$ thin films are discussed. These results will be helpful for better understanding $\mathrm{VO}_{\mathrm{x}}-\mathrm{CNTs}$ composite materials, and promoting further applications of such materials.
\end{abstract}

\section{Introduction}

Vanadium oxides are important semiconductors which have been widely applied in batteries, switches, supercapacitors, detectors et al. because of the layered structures, unique phase transition properties, and excellent electrical and optical properties [1]. With the rapid development of devices, further improvements on the chemical structures and physical properties of such materials are required. One of the most efficient ways to adjust the properties of $\mathrm{VO}_{x}$ is preparing composite materials, among which $\mathrm{VO}_{x}$-CNT composites have drawn considerable attentions $[2,3]$.

In 1995, Ajayan reported the first synthesis of $\mathrm{VO}_{x}$-CNT composites by annealing the mixture of partially oxidized nanotubes and $\mathrm{V}_{2} \mathrm{O}_{5}$ powder in air above the melting point of the oxide [2]. However, the chemical interactions between $\mathrm{VO}_{x}$ and CNTs were not investigated, and the applications of such materials were not reported. After that, $\mathrm{VO}_{x}$-CNT composites have been widely investigated. For example, Sakamoto fabricated $\mathrm{VO}_{x}$-SWCNT composites via a sol-gel method, which conductivity is three orders of magnitude higher than that of $\mathrm{VO}_{x}$ [4]. Willinger inspected the $\mathrm{V}_{2} \mathrm{O}_{4}$-CNT composites by atomic layer deposition (ALD), finding that the response of the hybrid material toward $\mathrm{NO}_{2}$ is enhanced after $\mathrm{CNT}$ addition [5]. Jampani improved the capacitance values of $\mathrm{VO}_{x}$ from $700 \mathrm{Fg}^{-1}$ to $1400 \mathrm{Fg}^{-1}$ at a scan rate of $2 \mathrm{mVs}^{-1}$ by deposit $\mathrm{VO}_{x}$ onto CNTs through APCVD [6]. Up to now, both MWCNTs and SWCNTs have been applied to fabricate the $\mathrm{VO}_{x}$-CNT composites. Unfortunately, the differences of the chemical structures and physical properties of $\mathrm{VO}_{x}$-MWCNT and $\mathrm{VO}_{x}$-SWCNT are unclear to date, which significantly obstruct further theoretical studies and practical applications of such composite materials.

Many methods, including ALD, CVD and hydrothermal, have been developed to prepare the $\mathrm{VO}_{x}$-CNT composites. However, these methods require expensive vacuum system and complicated manipulations. Rather differently, sol-gel is a simple, low-cost and convenient way to prepare composite materials, and especially, sol-gel has been successfully applied in fabricating $\mathrm{VO}_{x}$ thin film for uncooled microbolometers. In this work, we prepared both $\mathrm{VO}_{x}$-MWCNT and $\mathrm{VO}_{x}$-SWCNT composite films by sol-gel. Particularly, the influences of SWCNT and MWCNT on 
the chemical structures and physical properties of $\mathrm{VO}_{x}$ were systematically investigated.

\section{Experiment}

Vanadium pentaoxide powder was added to a mixed solution of benzyl alcohol and isobutanol with a molar ratio of 1:4:40. A reflux reaction at $110{ }^{\circ} \mathrm{C}$ for 4 hours was conducted to form the vanadium alkoxide. Then, the insoluble residues were removed by centrifuging at $2500 \mathrm{rpm}$ for 15 minutes, leaving light yellow $\mathrm{VO}_{x}$ sol.

Based on the as-prepared $\mathrm{VO}_{x}$ sol, $\mathrm{VO}_{x}$ films were spin-coated on the pre-treated substrates, and then they were annealed at $310{ }^{\circ} \mathrm{C}$ for 1 hour. In contrast, carboxyl-MWCNTs and carboxyl-SWCNTs powder were added in ethanol with the mass ratios of $0.5 \mathrm{wt} \%$, respectively, followed by a moderate ultrasonic treatment to form uniform mixtures. $\mathrm{VO}_{x}-\mathrm{MWCNT} / \mathrm{VO}_{x}-\mathrm{SWCNT}$ composite films were deposited on the similar substrates by alternately spin- coating of $\mathrm{VO}_{x}$ sol and spray-coating of functionalized MWCNTs/SWCNTs mixtures, and then they were similarly annealed. The products were systematically characterized by scanning electron microscopy (FEI INSPECT F), X-ray diffraction (Philips X'PertProMPD), Fourier infrared spectroscopy (PerkinElmer Spectrum 400) and high resistance meter (KEITHLEY 6517A), respectively.

\section{Results and Discussions}

The morphologies of the as-prepared thin films were imaged by SEM, and the typical images are displayed in Fig. 1. As shown in Fig. 1a, the $\mathrm{VO}_{x}$ film consists of rod-like grains and irregular bulk grains, indicating polycrystal in this case. Rather differently, $\mathrm{VO}_{x}$-MWNCT composite film is more like an amorphous structure because only fine and spherical grains appear in such material (Fig. 1b). In contrast, when SWCNTs are incorporated, a few rod-like grains appear in the $\mathrm{VO}_{x}$-SWNCT composite film, implying that the crystallinity of $\mathrm{VO}_{x}$-SWNCT composite film is lower than that of $\mathrm{VO}_{x}$ but higher than $\mathrm{VO}_{x}$-MWNCT composite film. One can see that agglomerations appear in the $\mathrm{VO}_{x}$-MWNCT composite film. This can be attributed to that the MWCNTs are easier to interact with each other through the functional groups because of stronger chemical activity [7]. In contrast, SWCNTs are uniformly dispersed, leading to the formation of homogenous $\mathrm{VO}_{x}-\mathrm{SWNCT}$ composite film. SEM images (Fig. 1) suggest that both MWCNTs and SWCNTs are chemically interacted with $\mathrm{VO}_{x}$, thus modifying the morphology and crystallinity of $\mathrm{VO}_{x}$ [3]. Moreover, the interactions between $\mathrm{VO}_{x}$ and MWCNTs seem stronger than those between $\mathrm{VO}_{x}$ and SWCNTs.
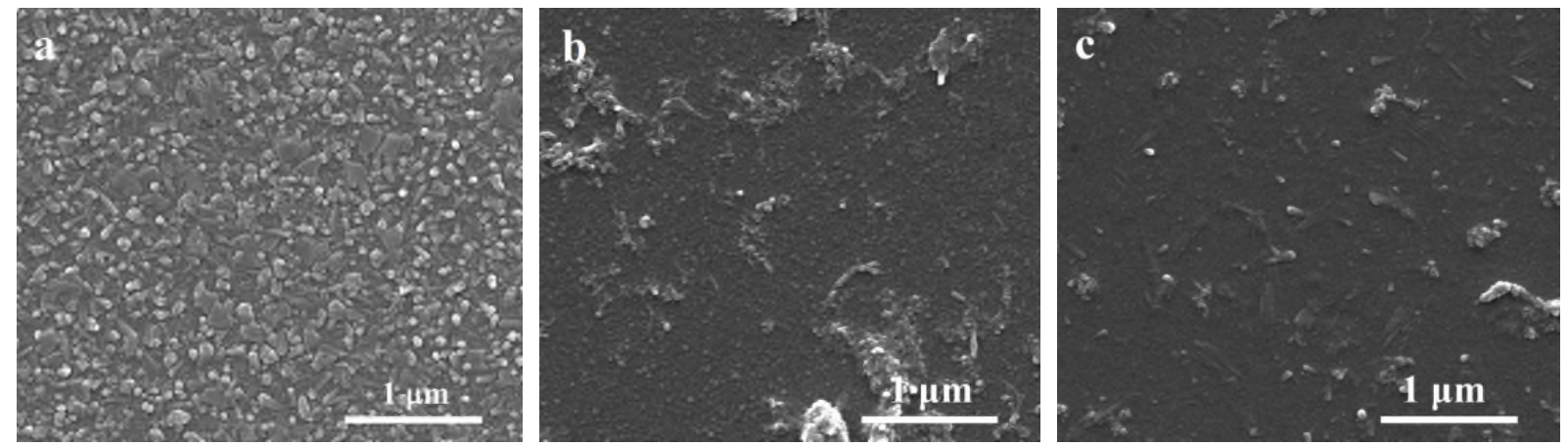

Fig. 1 SEM images of (a) $\mathrm{VO}_{\mathrm{x}}$ thin film, (b) $\mathrm{VO}_{\mathrm{x}}-\mathrm{MWCNT}$, and (c) $\mathrm{VO}_{\mathrm{x}}-\mathrm{SWCNT}$ composite films.

The crystallinity of the products was further characterized by X-ray diffraction (XRD), which results are shown in Fig. 2. As can be seen from the XRD patterns, two peaks at $8.1^{\circ}$ and $12.4^{\circ}$ assigned to the respective (200) plane of $\mathrm{V}_{3} \mathrm{O}_{7}$ (PDF\# 27-0940) and (200) plane of $\mathrm{V}_{2} \mathrm{O}_{5}$ (PDF\# 45-1074), are detected from the $\mathrm{VO}_{x}$ film, indicating that $\mathrm{VO}_{x}$ are polycrytal. In contrast, the $\mathrm{VO}_{x}$-MWCNT composite film is amorphous as no peak appears in the XRD pattern. Notably, the $\mathrm{V}_{2} \mathrm{O}_{5}$ peak disappears and only $\mathrm{V}_{3} \mathrm{O}_{7}$ peak appears in the $\mathrm{VO}_{x}$-SWCNT composite film, indicating reduction of $\mathrm{V}^{5+}$ by SWCNTs. XRD patterns verify that the crystallinity of $\mathrm{VO}_{x}$ can be significantly 
modified by MWCNTs and SWCNTs, in accordance with SEM images. Besides, according to the SEM images and XRD patterns of $\mathrm{VO}_{x}$ film and $\mathrm{VO}_{x}$-SWCNT composite film, one can deduce that the rod-like grains and the irregular grains in the SEM images correspond to the $\mathrm{V}_{2} \mathrm{O}_{5}$ crystal and the $\mathrm{V}_{3} \mathrm{O}_{7}$ crystal, respectively.

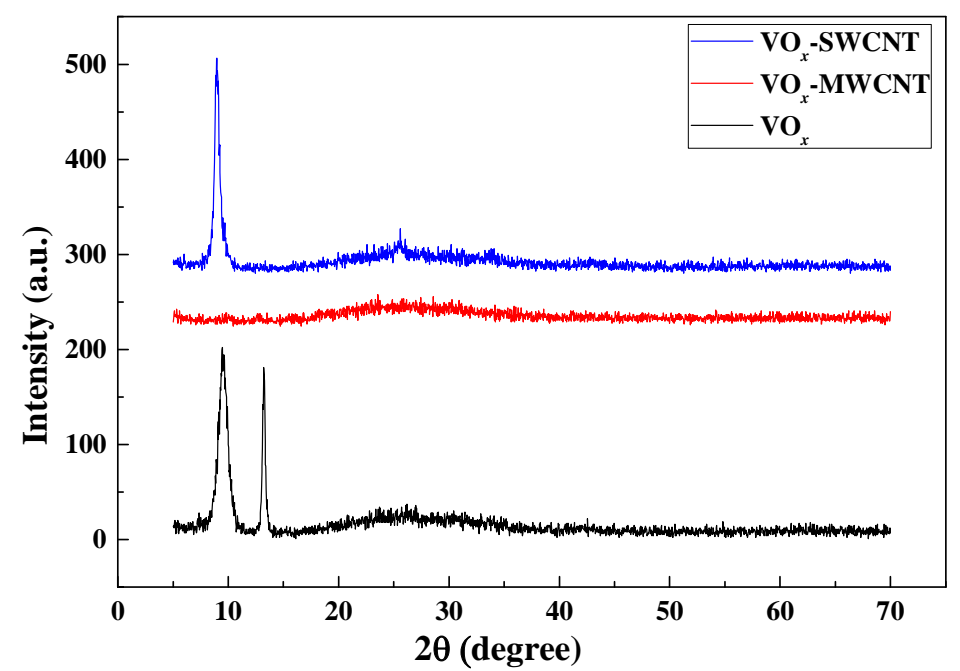

Fig. 2 XRD patterns of $\mathrm{VO}_{\mathrm{x}}$ thin film, $\mathrm{VO}_{\mathrm{x}}-\mathrm{MWCNT}$ and $\mathrm{VO}_{\mathrm{x}}-\mathrm{SWCNT}$ composite films.

Infrared spectroscopy (MIR) was employed to further characterize the chemical structures of $\mathrm{VO}_{x}$ and $\mathrm{VO}_{x}-\mathrm{CNT}$ composite films. Fig. 3a shows that three peaks at about $1006 \mathrm{~cm}^{-1}, 790 \mathrm{~cm}^{-1}$, and $510 \mathrm{~cm}^{-1}$, assigned to the respective stretching vibration of $\mathrm{V}=\mathrm{O}_{1}, \mathrm{~V}-\mathrm{O}_{2}-\mathrm{V}$, and bending vibration of $\mathrm{V}-\mathrm{O}_{3}$, were detected from the $\mathrm{VO}_{x}$ film $[8,9]$. After the MWCNT addition, the intensities of these three peaks are dramatically decreased, implying that the $\mathrm{VO}_{x}$ has been chemically interacted with MWCNTs through the $\mathrm{V}=\mathrm{O}_{1}, \mathrm{~V}-\mathrm{O}_{2}-\mathrm{V}$ and $\mathrm{V}-\mathrm{O}_{3}$ bonds, which will lead to the destruction of the layered $\mathrm{VO}_{x}$ structure. For the $\mathrm{VO}_{x}$-SWCNT composite film, the $\mathrm{V}=\mathrm{O}_{1}$ peak similarly turn weaker, but differently, the $\mathrm{V}-\mathrm{O}_{2}-\mathrm{V}$ and $\mathrm{V}-\mathrm{O}_{3}$ peak almost remain unchanged, suggesting that the $\mathrm{V}=\mathrm{O}_{1}$ is easier to interact with SWCNTs in the $\mathrm{VO}_{x}$-SWCNT composite film. It is worth noting that the $\mathrm{V}=\mathrm{O}_{1}$ contains two peaks at $\sim 1020 \mathrm{~cm}^{-1}$ and $\sim 997 \mathrm{~cm}^{-1}$, assigned to $\mathrm{V}^{5+}=\mathrm{O}$ and $\mathrm{V}^{4+}=\mathrm{O}$, respectively [10]. However, the $\mathrm{V}=\mathrm{O}_{1}$ peak of the $\mathrm{VO}_{x}$ film is close to $1020 \mathrm{~cm}^{-1}$ while the $\mathrm{V}=\mathrm{O}_{1}$ peaks of composite films are close to $997 \mathrm{~cm}^{-1}$, revealing that $\mathrm{VO}_{x}$ film contain more $\mathrm{V}^{5+}$, but more low valance state $\mathrm{V}$ ions appear in the composite film, as suggested by XRD (Fig. 2). This again manifests the redox reaction between $\mathrm{VO}_{x}$ and CNTs in the composite films. Close inspection reveals that a new peak at $\sim 884 \mathrm{~cm}^{-1}$ appears in both $\mathrm{VO}_{x}$-MWCNT and $\mathrm{VO}_{x}$-SWCNT composite film, as marked with a green line in Fig. 3b. According to Abello, hydrogen bonding with $\mathrm{O}_{1}$ atoms can weaken the $\mathrm{V}=\mathrm{O}_{1}$ bond, leading to the shift of $\mathrm{V}=\mathrm{O}_{1}$ peak to lower energy [8]. As revealed by SEM image, XRD patterns and FTIR spectra, the $\mathrm{VO}_{x}$ can chemically interacted with CNT. We have demonstrated that this kind of interaction happens between the oxygen in the $\mathrm{VO}_{x}$ and the functional groups in the CNT. Consequently, we attribute the peak at $\sim 884 \mathrm{~cm}^{-1}$ to the weakened $\mathrm{V}=\mathrm{O}_{1}$ bond, and the higher intensity of this peak in the $\mathrm{VO}_{x}$-MWCNT compared with that of $\mathrm{VO}_{x}$-SWCNT, again indicating stronger interactions between MWCNTs with $\mathrm{VO}_{x}$. The differences between the spectra of the $\mathrm{VO}_{x}$-MWCNT and $\mathrm{VO}_{x}$-SWCNT composite films verify that the interactions between $\mathrm{VO}_{x}$ and MWCNTs are stronger than those between $\mathrm{VO}_{x}$ and SWCNTs, in accordance with the SEM and XRD results, which is resulted from the higher chemical activity of MWCNTs. 

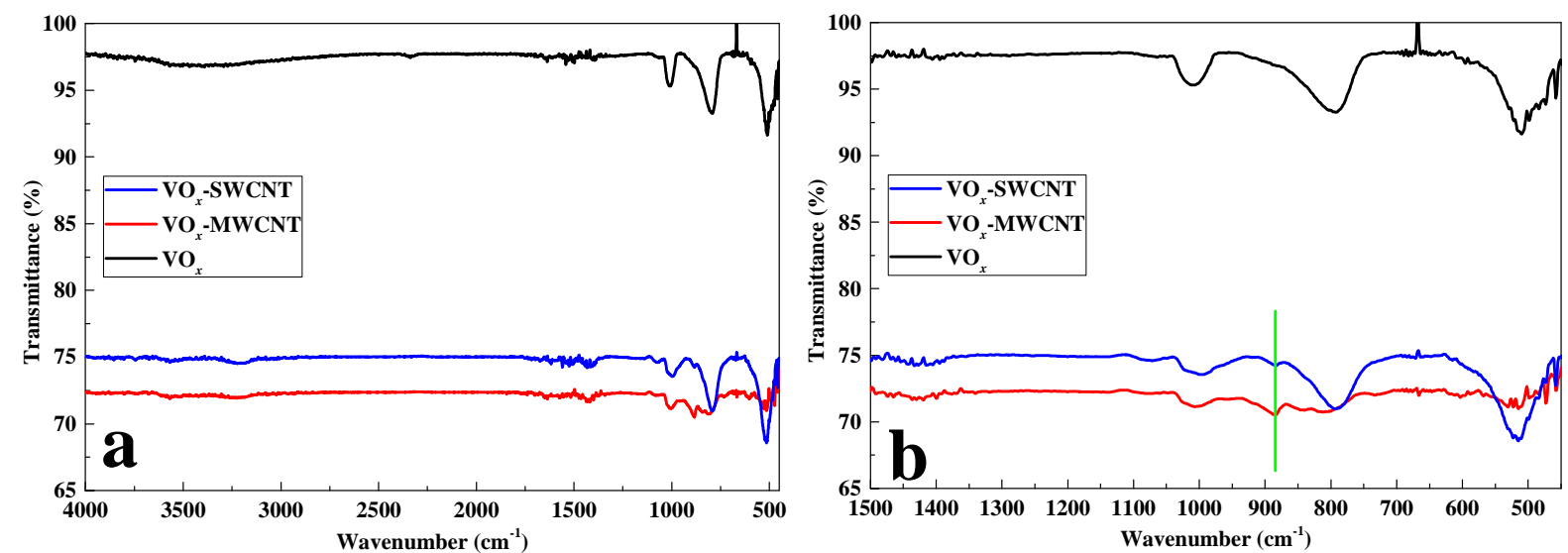

Fig. 3 (a) FTIR spectra of $\mathrm{VO}_{\mathrm{x}}$ thin film, $\mathrm{VO}_{\mathrm{x}}-\mathrm{MWCNT}$ and $\mathrm{VO}_{\mathrm{x}}-\mathrm{SWCNT}$ composite films, (b) FTIR spectra of the peaks between $1500 \mathrm{~cm}^{-1}$ and $450 \mathrm{~cm}^{-1}$ of the resulting films.

After the characterization of morphology and chemical structures of the resulting films, the electrical properties were also investigated. Fig. 4 illustrates the R-T plots of the $\mathrm{VO}_{x}$ and composite films, by which the TCR (defined as $\mathrm{TCR}=\mathrm{d}(\mathrm{Ln}(\mathrm{R})) / \mathrm{dT})$ of the products can be calculated. The resistance at room temperature $\left(R_{R T}\right)$ and $T C R$ of the $\mathrm{VO}_{x}$ film are $2.02 \mathrm{M} \Omega$ and $-2.05 \% \mathrm{~K}^{-1}$, respectively. After the CNT addition, the $R_{R T}$ of the $\mathrm{VO}_{x}$-MWCNT and $\mathrm{VO}_{x}$-SWCNT decreased to $416 \mathrm{k} \Omega$ and $990 \mathrm{k} \Omega$, respectively, indicating improved electrical conductivity. This is because that the CNTs can form conductive paths in the composite films, thus improving the electrical mobility. One can see that the TCR of $\mathrm{VO}_{x}$-MWCNT $\left(-1.40 \% \mathrm{~K}^{-1}\right)$ is much smaller than that of $\mathrm{VO}_{x}-\mathrm{SWCNT}$ $\left(-2.10 \% \mathrm{~K}^{-1}\right)$. This can be explained by that the interactions between $\mathrm{VO}_{x}$ and MWCNT are stronger than SWCNTs due to the higher chemical activity [7], leading to more lower valance state $\mathrm{V}$ ions, which decreases the work function of the $\mathrm{VO}_{x}$. As a consequence, the difference between the work function of $\mathrm{VO}_{x}$ and MWCNTs is smaller than that between $\mathrm{VO}_{x}$ and SWCNTs, resulting in a lower activation energy, as well as smaller TCR.

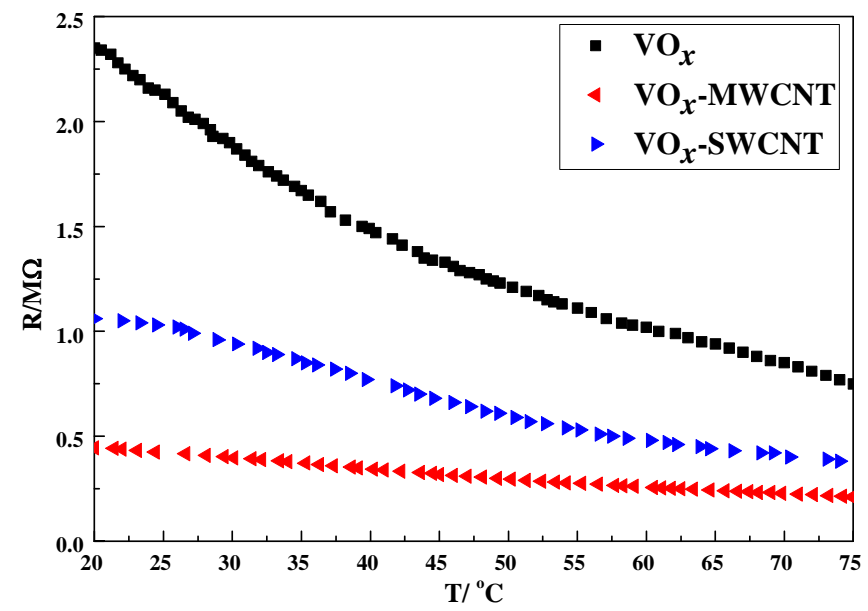

Fig. 4 R-T plots of $\mathrm{VO}_{\mathrm{x}}$ thin film, $\mathrm{VO}_{\mathrm{x}}-\mathrm{MWCNT}$ and $\mathrm{VO}_{\mathrm{x}}-\mathrm{SWCNT}$ composite films.

The chemical structure of $\mathrm{VO}_{x}$ prepared by sol-gel can be adjusted by both MWCNTs and SWCNTs through the chemical interactions between $\mathrm{VO}_{x}$ and CNTs, leading to the modifications of morphology, crystallinity, and electrical properties. Notably, the chemical activity of MWCNTs is higher than that of SWCNTs, leading to stronger interactions between the former with $\mathrm{VO}_{x}$, thus inducing drastic changes. However, the moderate interactions between $\mathrm{VO}_{x}$ and $\mathrm{SWCNTs}$ are helpful for introducing some new properties of SWCNTs under keeping some intrinsic properties of $\mathrm{VO}_{x}$, by which new composite materials with novel properties might be produced. 


\section{Conclusion}

In summary, we prepared $\mathrm{VO}_{x}$-MWCNTs and $\mathrm{VO}_{x}$-SWCNTs composite films by sol-gel. The physical and chemical properties of $\mathrm{VO}_{x}$ can be modified by both MWCNTs and SWCNTs. However, the interactions in these two composite films are different because of the difference in the chemical activity. MWCNTs can strongly interact with $\mathrm{VO}_{x}$, leading to formation of amorphous films with layered $\mathrm{VO}_{x}$ structure destroyed, and the electrical conductivity and TCR drastically decreased. In contrast, the $\mathrm{VO}_{x}$-SWCNTs composite films can retain some original properties of $\mathrm{VO}_{x}$, such as layered $\mathrm{VO}_{x}$ structure, high crystallinity and high $T C R$, due to the moderate interactions between $\mathrm{VO}_{x}$ and SWCNTs. This work illustrated the different influences of MWNCTs and SWCNTs on the properties of $\mathrm{VO}_{x}$, which will be helpful not only for further academic investigation of $\mathrm{VO}_{x}$-CNTs, but also for choosing desirable applications of various composites.

\section{Acknowledgement}

Financial support of this work by the National Natural Science Foundation of China (NSFC $61071032,61377063,61235006,61421002)$ is acknowledged.

\section{References}

[1] Y. Wang, G. Z. Cao, Developments in Nanostructured Cathode Materials for High-Performance Lithium-Ion Batteries, Adv. Mater. 20 (2008) 2251-2269.

[2] P. M. Ajayan, O. Stephan, PH. Redlich, C. Colliex, Carbon nanotubes as removable templates for metal oxide nanocomposites and nanostructures, Nature. 375 (1995) 564-567.

[3] Q. He, X. D. Xu, M. Wang, M. H. Sun, Y. D. Jiang, J. Yao, T. H. Ao, Chemical structures and physical properties of vanadium oxide films modified by single-walled carbon nanotubes, Phys. Chem. Chem. Phys. 18 (2016) 1422-1428.

[4] J. S. Sakamoto, B. Dunn, Vanadium oxide-carbon nanotube composite electrodes for use in secondary lithium batteries, J. Electrochem. Soc. 149 (2002) A26-A30.

[5] M. G. Willinger, G. Neri, E. Rauwel, A. Bonavita, G. Micali, N. Pinna, Vanadium oxide sensing layer grown on carbon nanotubes by a new atomic layer deposition process, Nano Lett. 8 (2008) 4201-4204.

[6] P. H. Jampani, K. Kadakia, D. H. Hong, R. Epur, J. A. Poston, A. Manivannan, P. N. Kumta, CVD Derived Vanadium Oxide Nano-Sphere-Carbon Nanotube (CNT) Nano-Composite Hetero-Structures: High Energy Supercapacitors, J. Electrochem. Soc. 160 (2013) A1118-A1127.

[7] H. Ago, T. Kugler, F. Cacialli, W. R. Salaneck, S. P. Shaffer Milo, A. H. Windle, Friend Richard H, Work functions and surface functional groups of multiwall carbon nanotubes, J. Phys. Chem. B. 103 (1999) 8116-8121.

[8] L. Abello, E. Husson, Y. Repelin, G. Lucazeau, Structural study of gels of V2O5: Vibrational spectra of xerogels, J. Solid State Chem. 56 (1985) 379-389.

[9] V. Brázdová, M. V. Ganduglia-Pirovano, J. Sauer, Periodic density functional study on structural and vibrational properties of vanadium oxide aggregates, Phys. Rev. B. 69 (1985) 165420.

[10] H. M. Oh, J. H. Kim, W. K. Lee, E. C. Lee, Fourier-transform infrared spectroscopy of hopping oscillations of electrons in vanadium oxide nanotubes, Appl. Phys. Lett. 102 (2013) 113105. 